\title{
Sistemas de produção de carne no Brasil e o passivo ambiental: uma revisão
}

\author{
Brazilians meat production systems and the environmental liability: a review \\ Los sistemas de producción de carne en Brasil y su responsabilidad ambiental: una revisión
}

\section{Resumo}

O Brasil figura entre os principais produtores de carne bovina, sendo o principal exportador deste alimento e detentor do segundo maior rebanho mundial. A produção de carne bovina brasileira, frequentemente vêm sendo associada como geradora de grande impacto ambiental, porém as particularidades do sistema de produção brasileiro baseado em pastagens costuma não ser levado em consideração. Em função destes fatos o objetivo desta revisão bibliográfica foi de reunir informações e discutir o passivo ambiental associado aos sistemas de produção de bovinos de corte no Brasil. Foi possível identificar, que há uma grande variação nas emissões entre os sistemas produtivos de acordo com a localização geográfica. A produção de bovinos em pastagens bem manejadas, bem como o emprego de algumas tecnologias como a suplementação, seja com alimentos volumosos ou concentrados visando reduzir o vazio forrageiro podem reduzir significativamente o passivo ambiental desta atividade. A emissão de gases do efeito estufa pela bovinocultura de corte brasileira é semelhante ou até mesmo inferior à dos demais países.

Palavras-chave: Bovinocultura de corte; Emissão de gases de efeito estufa; Sustentabilidade.

\section{Abstract}

Brazil is among the main beef producers, being the main exporter of this food and holder the second largest herd in the world. The production of Brazilian beef has often been associated as a generator of great environmental impact, but the particularities of the Brazilian production system based on pastures is usually not taken into account. Due these facts, the objective of this bibliographical review was gather information and discuss the environmental 
liabilities, associated with Brazilians beef cattle production systems. It was possible identify that are a large variation in emissions between production systems according to geographic location. The cattle production in well-managed pastures, as well the use of some technologies such supplementation, either with bulky or concentrated feed, in order to reduce the empty forage, can be significantly reduce the environmental liability of this activity. The emission of greenhouse gases by Brazilian beef cattle farming is similar or even lower than other countries.

Keywords: Beef cattle; Greenhouse gases emission; Sustainability.

\section{Resumen}

Brasil se encuentra entre los principales productores de carne de vacuno, siendo el principal exportador de este alimento y poseedor del segundo rebaño más grande del mundo. La producción de carne de vacuno brasileña se ha asociado a menudo como un generador de gran impacto ambiental, pero no se suelen tener en cuenta las particularidades del sistema de producción brasileño basado en pastos. Debido a estos hechos, el objetivo de esta revisión bibliográfica fue recopilar información y discutir los pasivos ambientales asociados con los sistemas de producción de ganado de carne en Brasil. Se pudo identificar que existe una gran variación en las emisiones entre los sistemas de producción según la ubicación geográfica. La producción de ganado en pastizales bien manejados, así como el uso de algunas tecnologías como la suplementación, ya sea con piensos voluminosos o concentrados, con el fin de reducir el vacío forrajero, puede reducir significativamente la responsabilidad ambiental de esta actividad. La emisión de gases de efecto invernadero por la ganadería de carne brasileña es similar o incluso menor que en otros países.

Palabras clave: Ganado vacuno; Emisiones de gases de efecto invernadero; Sustentabilidad.

\section{Introdução}

A bovinocultura de corte é uma importante atividade econômica no Brasil. O país está situado entre os maiores produtores de carne bovina do mundo há vários anos, destacando-se em tamanho do rebanho e quantidade de carne exportada. O rebanho bovino brasileiro voltou a crescer em 2019, após dois anos consecutivos em queda. A leve alta de 0,4\% garantiu ao país cerca de 214,7 milhões de cabeças, o que representa o segundo maior rebanho mundial (IBGE, 2020).

A produção de alimentos representa uma contribuição significativa para a carga ambiental e os impactos da criação de ruminantes são uma preocupação especial (Lesschen et al., 2011). Para alimentar a futura população humana de forma sustentável, é essencial buscar opções de mitigação de eventuais poluentes, buscando formas de produção que estejam ligadas a um menor impacto ambiental (Gerber et al., 2013). Os sistemas intensivos de criação de bovinos são correlacionados com maior uso de alimentos concentrados na dieta, o que está relacionado a geração de maiores volumes de gases causadores do efeito estufa (Steinfeld et al., 2006). Porém, esses sistemas também estão são associados a um melhor desempenho animal, podendo resultar em menor emissão de metano por quantidade de energia digestível ingerida (Mcal/dia).

Neste sentido, aperfeiçoar a nutrição animal pode ser um meio interessante visando melhorar a sustentabilidade dos sistemas de produção de carne bovina, porém, esses sistemas são bem distintos no Brasil em relação aos demais países. Suas particularidades estão relacionadas com a criação extensiva de grande parte dos animais. Este método de criação possui algumas vantagens, desvantagens e muitas divergências destacadas na literatura sobre o real passivo ambiental da produção brasileira de carne bovina. Em função das contradições anteriormente mencionadas, o objetivo desta revisão bibliográfica foi reunir informações e discutir o passivo ambiental associado aos sistemas de produção de bovinos de corte no Brasil.

\section{Metodologia}

O presente trabalho trata-se de uma revisão de literatura integrativa, visando sintetizar o conhecimento existente, que por muitas vezes, é contraditório sobre o tema em questão. Os artigos foram localizados pelos mecanismos de busca on-line das seguintes plataformas: Scientific Electronic Library (https://scielo.org); Portal de Periódicos Capes (https://www.periodicos.capes.gov.br); ScienceDirect (https://www.sciencedirect.com) e Google Scholar (http://scholar.google.com) entre os meses de maio a agosto do ano de 2021. As palavras chave utilizadas foram: passivo ambiental; bovinocultura de corte; produção de bovinos em forragens; sustentabilidade da produção pecuária. Uma vez 
localizados, os artigos foram classificados de acordo com a data de publicação, visando a obtenção de um banco de trabalhos o mais atualizado possível. Procedeu-se com a inclusão ou exclusão do trabalho no banco de artigos através da leitura do resumo de cada trabalho. Estudos que não estavam relacionados com o tema em questão ou publicados em revistas com baixo fator de impacto foram desconsiderados.

\section{Resultados e discussão}

\section{A emissão de poluentes pela criação de ruminantes}

De acordo com Steinfeld et al. (2006), cerca de 18\% das emissões globais de GEE (Gases de Efeito Estufa) são causadas de alguma forma pela produção pecuária. Isto está relacionado ao fato de os ruminantes produzirem $\mathrm{CH}_{4}$ (metano) durante a fermentação entérica da dieta. Outro fato que contribui para a produção de GEE na produção de ruminantes é a aplicação de fertilizantes nitrogenados sejam eles químicos ou as próprias fezes de ruminantes em lavouras. Esses processos geram a liberação de $\mathrm{CH}_{4}$ e $\mathrm{N}_{2} \mathrm{O}$ (Óxido Nitroso), o que resulta em aumento das emissões de $\mathrm{N}_{2} \mathrm{O}$ dos solos. Durante o processo de fabricação dos fertilizantes nitrogenados sintéticos também ocorre liberação de $\mathrm{CO}_{2}$ (Dióxido de Carbono) e $\mathrm{N}_{2} \mathrm{O}$ (Lesschen et al., 2011).

Modificar a produção de gases do metabolismo dos ruminantes, buscando menores produções de GEE é uma atividade muito complexa. Segundo Dick et al. (2021), entre 97,5 e 97,7\% da emissão desses gases são resultados da fermentação entérica, e a maior produção de $\mathrm{CH}_{4}$ ocorre durante a fermentação ruminal, e normalmente, representa uma perda de até $18 \%$ da energia bruta da dieta. Porém, ele atua como um aceptor de elétrons e dreno de hidrogênio $\left(\mathrm{H}_{2}\right)$, que é prejudicial a degradação microbiana dos materiais vegetais (Kozloski, 2016). Desse modo, o $\mathrm{CH}_{4}$ atua na promoção do crescimento microbiano, o que contribui para melhorar a digestibilidade do material consumido e sua mitigação será prejudicial ao bovino. Alguns estudos recentes avaliando a inclusão de alguns aditivos nas dietas como os taninos por exemplo são animadores, uma vez que apontaram potencial de redução nessas emissões, porém, mais estudos são necessários neste sentido.

Existem grandes variações na emissão de poluentes por kg de produto animal gerado entre os países. Essas variações, se devem principalmente pelas diferenças nos sistemas de produção animal, que podem ser relacionadas entre as interações genótipo do animal com o ambiente e também a grandes variações de ingredientes nas dietas, que afetam a conversão alimentar. O estudo de Leschen et al. (2011) avaliou as diferenças de eficiência e emissões de GEE para a produção animal entre as regiões da Europa. Este trabalho aponta que nos 27 países da União Europeia (UE), a pecuária teria um impacto no aquecimento global, sendo responsável por cerca de $10 \%$ das emissões totais de GEE. Em relação a quantidade de GEE emitido por $\mathrm{kg}$ de produto gerado dos principais produtos pecuários, a carne bovina aparece com 22,6 $\mathrm{kg} \mathrm{CO}$ - $\mathrm{eq} / \mathrm{kg}$, seguida pela carne suína com 3,5 $\mathrm{kg} \mathrm{CO}_{2}$-eq/kg, carne de frango com $1,6 \mathrm{~kg} \mathrm{CO}_{2}$-eq $/ \mathrm{kg}$, ovos com $1,7 \mathrm{~kg} \mathrm{CO} 2$-eq $/ \mathrm{kg}$ e leite a $1,3 \mathrm{~kg}$ $\mathrm{CO}_{2}-\mathrm{eq} / \mathrm{kg}$. Os autores apontam ainda algumas falhas no processo de quantificação dos dados, uma vez que a emissão de gases poderia ser ainda maior se o processamento de embalagens e a mudança de uso da terra na América Latina fossem quantificados, devido a UE importar significativos volumes de grãos para compor as dietas dessa região.

Diferentemente da bovinocultura de corte da UE, nos países da América Latina essa atividade é caracterizada por ocupar grandes áreas de pastagens. Esse fato, associado com a baixa densidade demográfica da população, permitiu que ali se estabelecessem sistemas produtivos de baixa eficiência (Braun et al., 2016). Esses sistemas, costumam ser bem conservadores e contam com uma baixa taxa de lotação, associada a técnicas de manejo tradicionais, fatores que resultam em baixa produtividade e maiores emissões de poluentes por kg de produto gerado (Gerber et al., 2015). Cabe ressaltar, que a avaliação 
sobre um sistema ser bom ou ruim não pode ser feita apenas sobre a emissão por kg de produto gerado. O que deve de fato ser levado em consideração é o saldo gerado, entre as emissões geradas e as mitigadas.

As pesquisas em nutrição animal têm se concentrado em melhorar a eficiência no uso de energia e proteína; no entanto, o potencial benefício ambiental dessas vias de pesquisa não foi bem investigado (White et al., 2015). Figueiredo et al, (2017) avaliando o balanço de gases de efeito estufa e a pegada de carbono na produção de bovinos de corte em pastagens no Brasil, identificaram grandes variações entre os sistemas produtivos associadas ás particularidades entre os biomas. $\mathrm{O}$ trabalho dos autores permite concluir que a produção de carne no país pode ser realizada com menores emissões de GEE em comparação com a produção da UE através da utilização de pastagens bem manejadas, e o emprego de sistemas integrados de produção como o Lavoura Pecuária Floresta (ILPF).

A globalização também vem permitindo a intensificação dos sistemas agrícolas da América do Sul, uma vez que os excedentes podem ser destinados à exportação, gerando renda. A intensificação está associada com maior uso de alimentos concentrados na dieta, e num primeiro momento, esse fato está relacionado com maiores volumes de GEE (Steinfeld et al., 2006). O maior fornecimento de alimentação concentrada esta correlacionada com maiores emissões em função da dieta rica em energia e proteína para animais de alta produção (Bakken et al., 2017).

Porém, com a maior participação de grãos na dieta ocorre um aumento no consumo de energia por unidade de peso do animal. Esse fato não gera apenas um aumento na produção de metano $(\mathrm{kg} / \mathrm{dia})$, mas também melhor desempenho animal, podendo resultar em menor emissão de metano por quantidade de energia digestível ingerida (Mcal/dia). Assim, nem sempre a maior produção de metano diária é indicativa de ineficiência dos processos metabólicos ou de perda de energia, já que pode ser oriunda da melhor qualidade da dieta consumida pelos animais (Brunes \& Couto, 2017).

Outro ponto importante a ser considerado é que os ruminantes podem ser alimentados com resíduos e coprodutos industriais, gerando alimentos de alto valor biológico a partir de produtos que não seriam aproveitados na alimentação humana (Andreini et al., 2019). Do mesmo modo, a comparação entre os sistemas produtivos intensivos com extensivos deve ser realizada com cautela e observando alguns fatores relevantes. Quando as gramíneas são bem manejadas, os animais possuem maior eficiência produtiva, e o sistema produtivo pode exercer papel de agente sequestrador de GEE e não apenas como agente poluidor (WANG, 2015).

Pastagens cultivadas em boas condições podem inclusive acumular maior quantidade de carbono, por meio da captura e estocagem de $\mathrm{CO}_{2}$ da atmosfera do que os animais inseridos no sistema são capazes de liberar, (Ruggieri \& Cardoso, 2017), o que não foi considerado por Leschen et al. (2011) uma vez que esse sistema produtivo é pouco comum na UE em função das adversidades climáticas.

Alguns estudos já demonstraram que é possível obter taxas de sequestro de carbono de até $1765 \mathrm{~kg} / \mathrm{ha} / \mathrm{ano}$, ao trabalhar com sistemas forrageiros estáveis e bem consolidados (Wang, 2015), e que maiores emissões de GEE por kg de produto gerado estariam associadas com sistemas produtivos baseados em pastagens degradadas ou com baixo potencial produtivo e consequentemente baixos índices zootécnicos (Figueiredo et al., 2017).

\section{A bovinocultura de corte brasileira}

A importância da Pecuária de Corte para o país fica evidente ao analisar o PIB desta atividade, que em 2019 foi de R\$ 618,50 bilhões, valor que está intimamente associado com o tamanho do rebanho e ao fato de o país ser o maior exportador mundial dessa commoditie (Abiec, 2020). A grande disponibilidade de pastagens, possibilitou ao país atingir o segundo maior rebanho mundial, com cerca de 214,7 milhões de cabeças, com um crescimento de 0,4\% em 2019 após dois anos em queda (Usda, 2021). Essa grande disponibilidade de pastagens, resulta em um sistema produtivo com baixos custos de produção, manejo simplificado e boas condições relacionadas ao conforto e bem-estar animal (Brunes \& Couto, 2017). 
As dimensões continentais do Brasil também resultam em grande diversidade climática e ecológica caracterizando os biomas, tornando o conhecimento das peculiaridades regionais essencial para alinhar as práticas produtivas visando a sustentabilidade (Dick et al., 2021). A definição do significado da palavra Bioma é complexa. De forma bem resumida, para a classificação de um bioma, são levados em consideração além da aparência geral da vegetação, todas as formas de vida nele inseridos e seus ritmos de crescimento e reprodução (Batalha, 2011). Os limites entre as unidades de federação e os Biomas brasileiros estão demonstrados na Figura 1.

Segundo o Ministério do Meio Ambiente (MMA) (2021), a Amazônia é o maior bioma brasileiro, abrangendo uma área de 4,196.943 milhões de $\mathrm{km}^{2}$ (49,29 \% do território brasileiro). Neste local, crescem 2.500 espécies de árvores (um-terço de toda a madeira tropical do mundo) e 30 mil espécies de plantas. Essa riqueza natural se contrapõe aos baixos índices socioeconômicos da região, com baixa densidade demográfica e crescente urbanização. Desse modo, visando a sustentabilidade da produção de carne nesta região, é fundamental que esta atividade não resulte em desmatamentos.

O Cerrado é o segundo maior bioma do país, ocupa 23,92\% do território nacional e é reconhecido como a maior savana do mundo, além de possuir a nascente das maiores bacias hidrográficas da América do Sul (MMA, 2021). Este Bioma apresenta clima tropical com invernos secos e duas estações bem definidas ao longo do ano e alto potencial de produção agropecuária após a correção da fertilidade do solo. A baixa produção de matéria-seca por sua vez, é típica da vegetação nativa ocorre em função do alto grau de intemperização, da baixa fertilidade do solo e alta degradabilidade da matéria orgânica, ocasionados pela grande variação dos fatores temperatura e umidade (Carvalho et al., 2010). Paralelamente a estes fatos, pelas características apresentadas, atualmente há uma discussão sobre o cerrado não ser apenas um bioma, mas sim um complexo de biomas (Batalha, 2011).

Já o bioma Pampa no Brasil, está restrito ao estado Rio Grande do Sul, mas também abrange outros países, como Uruguai e Argentina. Este bioma é caracterizado como um ecossistema campestre e com vegetação composta predominantemente por gramíneas e arbustos, mas também possui áreas de vegetação mais densa, áreas alagadas e áreas montanhosas com diversos tipos de cobertura vegetal (MMA, 2021). Essas características, tornaram a bovinocultura de corte uma atividade tradicional e uma das principais atividades econômicas desta região, sendo reconhecida inclusive, como parte fundamental na conservação das características fundamentais deste bioma (Pillar et al., 2012).

O Pantanal por sua vez, é o menor dos biomas brasileiros, ocupando apenas 1,76\% do território. O clima é semelhante ao do Cerrado, com invernos secos e verões chuvosos. O território deste Bioma apresenta a maior planície inundável do planeta, que ocupa aproximadamente 15.035.500,00 hectares (MMA, 2021). Em função dessa particularidade, é comum os pecuaristas deslocarem os animais para áreas mais elevadas na época de cheias dos rios, podendo realoca-los nas áreas mais baixas apenas nas estiagens. 
Figura 1: Limites estaduais e os Biomas brasileiros.

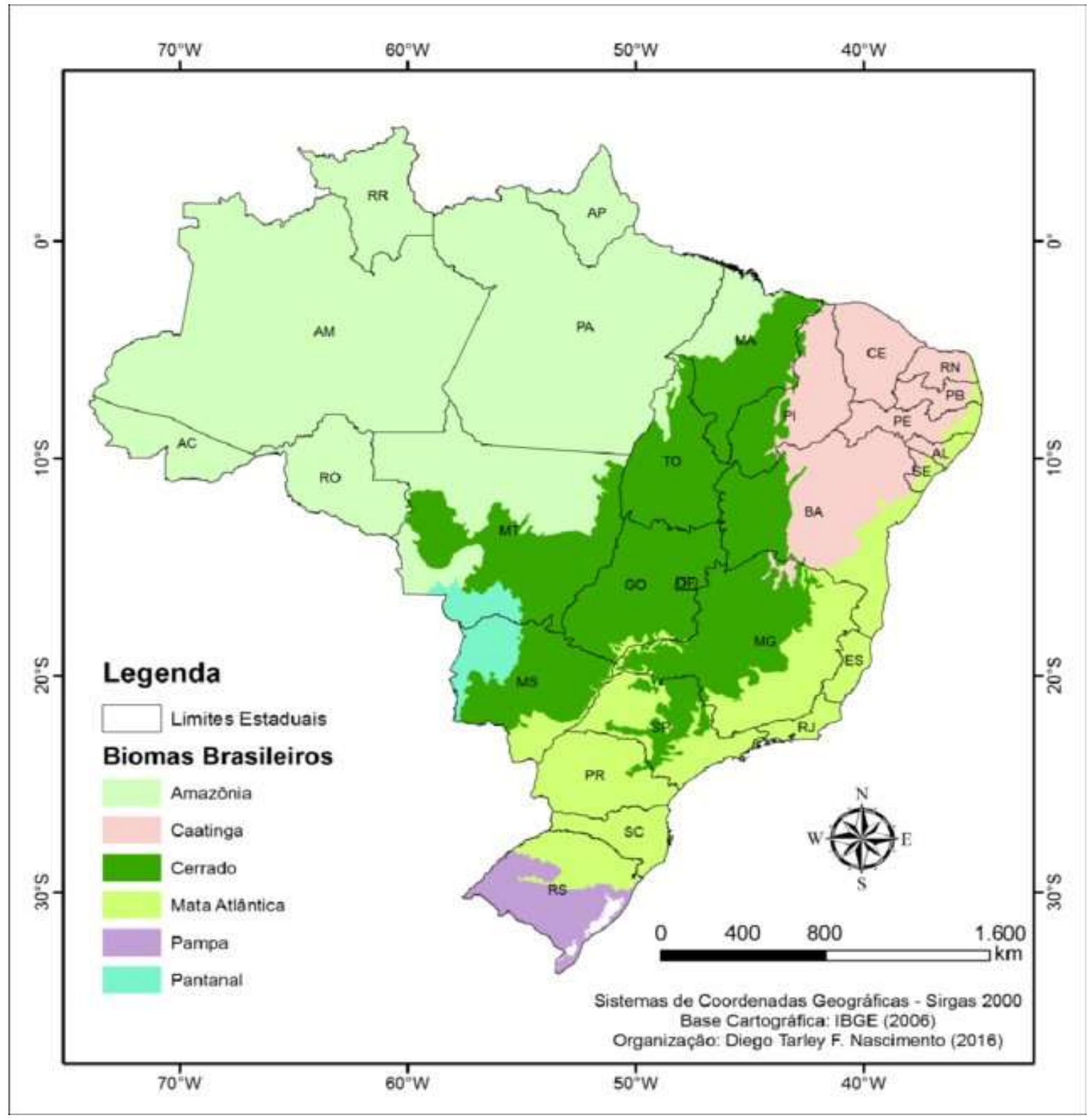

Fonte: Carneiro e Santos (2019)

Dick et al. (2021) analisaram o impacto potencial dos sistemas de produção típicos destes quatro principais biomas brasileiros para a bovinocultura de corte e alguns resultados deste trabalho estão expressos na Tabela 1. É possível observar grandes diferenças entre a área de abrangência de cada bioma no país. Essa característica, juntamente com o tipo de vegetação predominante e a presença de chuvas acabam impactando a habilitação agropecuária dos biomas e são refletidas no tamanho do rebanho bovino e por consequência na organização de toda uma cadeia produtiva.

De modo geral, é possível identificar valores semelhantes ou menores de GEE emitido por kg de produto gerado no Brasil em comparação com os demais países. Os autores justificaram a maior intensidade de GEE atribuída ao Pantanal em função da pecuária de corte deste bioma ser voltada a produção de bezerros, e que a fase vaca-bezerro representa mais da metade das emissões totais $(51,4-63,7 \%)$ desses gases. A maior intensificação nos sistemas de produção de bovinos na Amazônia e no Cerrado contribuir com maiores taxas de parição e consequentemente, maior produção de bovinos em relação ao número de matrizes presentes. Ainda nesses dois biomas, a intensificação foi apontada como responsável por reduzir a 
idade das fêmeas ao primeiro parto, fato que contribui para a menor intensidade de emissão de GEE por kg de peso vivo produzido.

Tabela 1: Comparação entre os 4 principais Biomas brasileiros para a Bovinocultura de Corte.

\begin{tabular}{lcccc}
\hline & Amazônia & Cerrado & Pampa & Pantanal \\
\hline Área total (ha) & 419.694 .300 & 203.644 .800 & 17.649 .600 & 15.035 .500 \\
Rebanho bovino (cabeças) & 62.715 .553 & 76.663 .769 & 8.909 .704 & 5.742 .167 \\
Emissão de GEE $\left(\mathrm{tCO}_{2}\right)$ & 1958 & 1841,52 & 1814,62 & 2009.83 \\
Produção de carne $(\mathrm{kg} \mathrm{PV})$ & $140.681,69$ & $152.210,54$ & $124.142,19$ & $94.873,58$ \\
Intensidade de GEE $\left(\mathrm{kgCO}_{2} / \mathrm{kg} \mathrm{PV}\right)$ & 13,92 & 12,1 & 14,62 & 21,18 \\
\hline
\end{tabular}

Fonte: Adaptado de Dick et al. (2021).

\section{Em busca da maior sustentabilidade na pecuaria de corte}

Maiores exigências do mercado consumidor de carne bovina relacionadas a produção sustentável desse produto foram observadas nas últimas décadas. Em função do rebanho brasileiro numeroso, surgem debates relacionados ao impacto que este causa no ambiente onde os animais estão inseridos. Entre outros fatores, este impacto pode ser visualizado através do consumo de água. Considerando o consumo de água pelos animais em produção, a maior participação é dos bovinos (corte, leite, tração, ...) com cerca de $88 \%$, seguido por suínos 5\% e aves domésticas 2\% (Flachsbarth et al., 2015). Cabe destacar, que os autores atribuíram apenas $10,8 \%$ do gasto de água no Brasil a produção animal, onde a agricultura foi responsável por $79 \%$ e a irrigação por $68,4 \%$ do consumo total de água.

A preocupação do país em relação em relação a sustentabilidade na produção pecuária pode ser notada em 2012 no Plano Brasileiro de Mitigação e Adaptação às Mudanças Climáticas. Nesse plano, a recuperação de 15 milhões de hectares de pastagens degradadas até 2020 e prevenir a degradação de novas pastagens por meio de manejo correto era um dos principais compromissos (Brasil, 2012). No ano de divulgação do plano, estimava-se, que entre 27 e $42 \%$ dos 190 dos milhões de hectares de pastagens cultivadas, estivessem em algum estado de degradação no país (Silva et al., 2013). Em pastagens bem manejadas, é possível obter ganhos de peso diário por hectare superiores a $4 \mathrm{~kg}$ (Viana et al., 2020), o que demonstra uma grande possibilidade de incremento na produção de carne brasileira. Além disso, estes dados mostram que o país apresenta grande potencial para mitigação de GEE por meio da recuperação das áreas de pastagens degradadas, contribuindo para a remoção do $\mathrm{CO}_{2}$ atmosférico. Contudo, atualmente a divulgação de metas alcançadas e resultados obtidos pelo referido plano mostra-se deficiente.

Alguns erros básicos como a determinação equivocada da oferta e da demanda de forragem podem resultar em má nutrição dos animais, menor desempenho e degradação do pasto. Quando um sistema de produção é baseado em pastagens degradadas, os animais possuem maior exigência de energia para mantença, uma vez que há um gasto considerável de nutrientes com o deslocamento até a ingestão de forragem esgotar a capacidade física do rúmen, e em casos mais graves, este esgotamento não chega a ocorrer (Moraes et al., 2009). A produção baseada em pastagens também apresenta algumas desvantagens em função da estacionalidade forrageira, relacionada a variação das condições climáticas entre as estações nos países tropicais. Essas variações resultam, além da baixa disponibilidade, forragem de baixo valor nutricional em determinado período do ano. O valor nutritivo das plantas piora com o avanço da estação seca, resultando em maiores teores de fibras e lignina (Silva et al., 2009). 
Os bovinos, através da sua microbiota ruminal, são capazes de obter energia a partir de fibras com digestibilidade baixa das plantas mesmo com a presença de lignina, alimentos sem valor para o consumo humano. Nos períodos de vazio forrageiro, é comum que a parte foliar das plantas esteja em estado avançado de senescência e seu conteúdo celular morto, consequentemente o material apresenta baixo teor proteico. As bactérias do rúmen precisam de proteína para digerir as fibras, e assim transformá-las em energia (Van Soest, 1994), dessa forma, a suplementação proteica em determinado período para manter os microrganismos ruminais e incrementar a digestibilidade da dieta pode ser uma estratégia interessante para o pecuarista, visando melhorar o desempenho animal no período das secas ou inverno, dependendo da sua localização.

A produção de forragem, bem como a composição botânica das plantas acabam variando ao longo do ciclo produtivo (Viana et al., 2020). Em função disso, é interessante destacar que a suplementação em baixos níveis, é válida para estimular o consumo de pasto, uma vez que a mesma tende a não promover maior ganho de peso dos animais (Porto et al., 2011). Deste modo, quando a pastagem está em um estado avançado de degradação, é necessário que o nível de suplementação seja mais elevado e a mesma balanceada de forma a fornecer os nutrientes em falta, de modo que possa atender as exigências do animal e ocorrer uma redução no consumo de forragem (Girardi et al., 2021). Com maior nível de suplementação, é possível reduzir a frequência de pastejo, permitindo que ocorra a recuperação do índice de área foliar das plantas, que foi removido anteriormente pelo pastejo e consequentemente maximizar a taxa de lotação.

O pastejo é um estímulo para a rebrotação, no entanto, é necessário que a planta possua um índice de área foliar adequado e maximizar o processo de fotossíntese e logo, seu crescimento (Manço, 2020). Animais suplementados, fazem menor uso do pasto. Adams et al. (2021) concluíram que a suplementação com alimento concentrado reduz a frequência de pastejo de vacas no pasto nativo do Bioma Pampa. Nessa categoria, é comum ocorrer um déficit nutricional no terço final da gestação e nas primeiras semanas pós-parto, fato que é refletido em baixos índices produtivos na pecuária de corte (Klein et al., 2021). Durante o período em que estão submetidos a subnutrição, os animais mobilizam as reservas corporais, perdem peso e apresentam quadro de balanço energético negativo, podendo comprometer a atividade reprodutiva subsequente (Klein et al., 2021).

A suplementação através do fornecimento de forragens conservadas também é uma alternativa viável para garantir o fornecimento de nutrientes em quantidade adequada durante o período de escassez de alimentos (Freitas et al., 2006). A melhoria na qualidade do volumoso ofertado aos animais, além de aumentar a eficiência alimentar e o desempenho, promove redução da produção de gás $\mathrm{CH}_{4}$ por animal e incremento no desempenho (Brunes \& Couto, 2017).

A forma de conservação entre os materiais é um pouco distinta, enquanto que o feno se conserva pela desidratação da forragem, o material pré-secado e a silagem são conservados através de um processo de fermentação. A ensilagem é um dos processos mais difundidos para a conservação de alimentos volumosos. A silagem de capins possui algumas vantagens interessantes como a elevada produção anual por área, menor custo por tonelada de nutrientes produzidos, perenidade, baixo risco de perda e maior flexibilidade de colheita. Em contrapartida, possui geralmente baixo teor de carboidratos solúveis, necessários para uma fermentação adequada, baixo teor de MS no momento do corte, alto poder tampão e menor teor energético em comparação ao milho ou sorgo (Ribeiro et al., 2009).

A produção do alimento pré-secado é uma alternativa para alguns locais onde o processo de fenação costuma ser prejudicado pela ocorrência de chuvas. A precipitação após o corte e, portanto, o período de secagem do material cortado até seu enfardamento resulta em significativas perdas de qualidade na forragem, e em alguns casos pode resultar até em perda total da forragem cortada (Girardi et al., 2021). Diante do exposto, a intensificação pode ser uma estratégia importante para reduzir o passivo ambiental na bovinocultura de leite e de corte (Bakken et al., 2017). De modo geral, sistemas de produção mais intensivos, podem ser relacionados com maior produção de alimento volumoso conservado. Essa prática, permite melhorar a eficiência na utilização das áreas pastoris e consequentemente, maior alojamento de animais no sistema produtivo, 
especialmente em propriedades com áreas reduzidas, que podem optar pela compra desse tipo de alimento (Girardi et al., 2021). Segundo os mesmos autores, quando as plantas forrageiras são submetidas ao pastejo, geralmente apresentam respostas diferentes daquelas submetidas ao corte mecânico. Os principais motivos para essa ocorrência são a seletividade animal, os danos físicos causados pelo pisoteio, retorno de nutrientes através de fezes e urina, deposição de saliva e compactação do solo.

Mudanças significativas, e avanços em praticamente todos os indicadores zootécnicos podem ser observados no sistema produtivo de bovinos de corte. De 2001 a 2019, o número de bovinos confinados no país cresceu acima de 295\% (Palhares et al., 2021). Em 2019, 6,09 milhões de bovinos foram abatidos oriundos desse sistema de produção (ABIEC, 2020). Apesar desse expressivo crescimento, considerando o total de bovinos abatidos, o confinamento representa apenas cerca de 14\%. Os sistemas confinados proporcionam maior facilidade de manejo além de maior conforto térmico aos animais uma vez que permitem a utilização de diferentes métodos de climatização. Outra vantagem desse tipo de sistema de produção é a possibilidade do manejo adequado dos dejetos por meio da utilização de biodigestores por exemplo, contudo, ainda não há trabalhos quantificando dados sobre a adoção desta tecnologia no Brasil.

O confinamento também permite a mecanização das atividades de limpeza de baias, processamento e fornecimento da dieta aos animais, o que resulta em uma diminuição na demanda de mão de obra por animal abatido. Recentemente, produtores vem relatando grandes dificuldades relacionadas com a mão de obra nas atividades agropecuárias e a menor disponibilidade de mão de obra no campo tende a resultar na intensificação dos sistemas produtivos agropecuários (Girardi et al., 2021). Desse modo, o crescimento da produção em confinamento, entre outros fatores, pode estar relacionado com a escassez de mão de obra. Contudo, os processos para obtenção de alguns alimentos clássicos de confinamentos como a ensilagem e fenação são trabalhosos, onerosos e dependentes de espécies e/ou cultivares forrageiras produtivas, de mão de obra treinada e implementos específicos (Freitas et al., 2006). A inclusão de alimento volumosos no confinamento é bastante difundida, uma vez que possibilita a inclusão de fibra fisicamente efetiva na dieta do rebanho. Esse tipo fibra é responsável por estimular a atividade mastigatória, e a secreção salivar, visando a saúde do rúmen, pois é de suma importância manter o ambiente ruminal estabilizado e otimizado (Girardi et al., 2021).

Entre as vantagens do sistema de semiconfinamento, pode-se destacar o menor custo com a alimentação (concentrado e volumoso) além da demanda inferior de investimento com instalações. O semiconfinamento por sua vez, além de apresentar o custo com alimentação concentrada, costuma resultar em alta compactação do solo e consequentemente, redução de produtividade das plantas forrageiras ali implantadas e posteriormente, gastos com a descompactação mecânica da área (Mota et al., 2020). Utilizar alimentos com maior concentração energética, tais como a silagem de milho ou de grãos, em substituição a gramíneas, pode reduzir a emissão de metano pelos ruminantes. A melhoria da qualidade da dieta, através do aumento da digestão, promove aumento da taxa de passagem no rúmen, o que resulta em menor produção de $\mathrm{H}_{2} \mathrm{e}$, consequentemente, de metano (Janseem, 2010). Isso porque a presença de amido dos grãos na dieta, além de favorecer a produção de propionato, promove aumento do consumo voluntário, o que, consequentemente, reduz o tempo de retenção da digesta no rúmen e restringe a fermentação ruminal (Goularte et al., 2011).

A intensificação do pastejo e a introdução de espécies forrageiras mais produtivas também deve ser avaliada, uma vez que podem representar novas oportunidades de agregação de valor, e conservação de áreas sensíveis encontradas em diferentes ambientes que compõem a diversidade da produção pecuária brasileira e refletir positivamente sobre a qualidade de vida do pecuarista brasileiro (Dick et al., 2021).

\section{Considerações Finais}

A importância da pecuária também está relacionada com a conversão de alimentos residuais em alimentos de valor 
biológico elevado para humanos (carne, leite, ...). A emissão desses gases pode ser reduzida com a criação dos animais em sistemas produtivos baseados em pastagens bem manejadas, com a suplementação estratégica em períodos de vazio forrageiro. Mudanças na dieta e a intensificação de sistemas produtivos de ruminantes podem melhorar o valor ambiental dos seus produtos.

A emissão de gases do efeito estufa por pela bovinocultura de corte brasileira é semelhante ou até mesmo inferior aos demais países produtores desta commoditie, o que de certa forma, pode ser considerado uma quebra de paradigma. Neste sentido, a maior divulgação desses resultados pode ser benéfica para toda a cadeia produtiva.

\section{Referências}

ABIEC - Associação Brasileira da Indústria Exportadora de Carne. (2020). Beefreport: perfil da pecuária no Brasil.

Adams, S. M., Klein, J. L., Machado, D. S., Rodrigues, L. S., Brondani, I. L., Alves Filho, D. C., Cocco, J. M., Maidana, F. M., Oliveira, G. A., Teixeira, M. D., \& Sousa, R. L. (2021). Comportamento ingestivo de vacas de corte submetidas a diferentes níveis nutricionais no terço final da gestação. Research, Society and Development, 10(7). http://dx.doi.org/10.33448/rsd-v10i7.16555.

Andreini, E., Finzel, J., Rao, D., Larson-Praplan, S., \& Oltjen, J. W. (2019). Estimation of the requirement for water and ecosystem benefits of cow-calf production on California Rangeland. Rangelands, 40, 24-32. https://doi.org/10.1016/j.rala.2017.12.001.

Bakken, A. K., Daugstad, K., Johansen, A., Hjelkrem, A. G. R., Fystro, G., Strømman, A. H., \& Korsaeth, A. Environmental impacts along intensity gradients in Norwegian dairy production as evaluated by life cycle assessments. Agricultural Systems, 158, 50-60, 2017. DOI: http://dx.doi.org/10.1016/j.agsy.2017.09.001.

Batalha, M. A. (2011). The Brazilian cerrado is not a biome. Biota Neotropica, 11(1). https://doi.org/10.1590/S1676-06032011000100001.

Brasil, (2012). Plano ABC (Agricultura de Baixa Emissão de Carbono). Ministério da Agricultura, Pecuária e Abastecimento, Ministério do Desenvolvimento Agrário e MAPA/ACS, Brasília/DF, 173.

Braun, A., Van Dijk, S., \& Grulke, M. (2016). Upscaling silvopastoral systems in South America. InterAmerican Development Bank.

Brunes, L. C., \& Couto, V. R. M. (2017). Balanço de gases de efeito estufa em sistemas de produção de bovinos de corte. Archivos de Zootecnia, 66(254), 287-299. https://doi.org/10.21071/az.v66i254.2334.

Carneiro, V. A., \& Santos, J. C. V. (2019). O matraquear das águas no cerrado. SAMA / UEG, 246.

Carvalho, J. L. N., Avanzi, J. C., Silva, M. L. N., Mello, C. R. D., \& Cerri, C. E. P. (2010). Potencial de sequestro de carbono em diferentes biomas do Brasil. Revista Brasileira de Ciência do Solo, 34(2), 277-290. https://doi.org/10.1590/S010006832010000200001

Dick, M., Da Silva, M. A., Da Silva, R. R. F., Ferreira, O. G. L., Maia, M. S., De Lima, S. F., Neto, V. B. P., Dewes, H. (2021). Environmental impacts of Brazilian beef cattle production in the Amazon, Cerrado, Pampa, and Pantanal biomes. Journal of Cleaner Production, 311 , 15. https://doi.org/10.1016/j.jclepro.2021.127750.

Figueiredo, E. B., Jayasundara, S., Oliveira Bordonal, R., Berchielli, T. T., Reis, R. A., Wagner-Riddle, C., \& La Scala Jr, N. (2017). Greenhouse gas balance and carbon footprint of beef cattle in three contrasting pasture-management systems in Brazil. Journal of Cleaner Production, 142, 420-431. http://dx.doi.org/10.1016/j.jclepro.2016.03.132.

Flachsbarth, I., Willaarts, B., Xie, H., Pitois, G., Mueller, N. D., Ringler, C., \& Garrido, A. (2015). The Role of Latin America's Land and Water Resources for Global Food Security: Environmental Trade-Offs of Future Food Production Pathways. Plos One, 10(1), 0116733. https://doi.org/10.1371/journal.pone.0116733.

Freitas, A. W. P., Pereira, J. C., Rocha, F. C. Costa, M. G., Leonel, F. De P., \& Ribeiro, M. D. (2006). Avaliação da qualidade nutricional da silagem de canade-açúcar com aditivos microbianos e enriquecida com resíduo da colheita da soja. Revista Brasileira de Zootecnia, 35(1), 38-47. https://doi.org/10.1590/S1516-35982006000100005.

Gerber, P. J., Mottet, A., Opio, C. I., Falcucci, A., \& Teillard, F. (2015). Environmental impacts of beef production: review of challenges and perspectives for durability. Meat Science, 109, 2-12. https://doi.org/10.1016/j.meatsci.2015.05.013.

Gerber, P. J., Steinfeld, H., Henderson, B., Mottet, A., Opio, C., Dijkman, J., Falcucci, A., \& Tempio, G. (2013). Tackling climate change through livestockA global assessment of emissions and mitigation opportunities. FAO, Rome, Italy.

Girardi, D., Prestes Júnior, H. S., Battiston, J., Sordi, A., \& Cericato, A. (2021). Viabilidade técnica e econômica do uso de aditivos em silagem pré-secada de capim tifton 85 (Cynodon dactylon). Brazilian Journal of Development, 7(6), 56887-56917. https://doi.org/10.34117/bjdv7n6-207.

Goularte, S. R., Itavo, L. C. V., Santos, G. T., Itavo, C. C. B. F., Oliveira, L. C. S., Favaro, S. P., Dias, A. M., Torres Junior, R. A. A., \& Bittar, C. M. M. (2011). Ácidos graxos voláteis no rúmen de vacas alimentadas com diferentes teores de concentrado na dieta. Arquivo Brasileiro de Medicina Veterinária e Zootecnia, 63, 1479-1486. https://doi.org/10.1590/S0102-09352011000600027. 
Ibge, Instituto Brasileiro de Geografia e Estatística. (2020). PPM 2019: após dois anos de queda, rebanho bovino cresce 0,4\%. https://agenciadenoticias.ibge.gov.br/agencia-sala-de-imprensa/2013-agencia-de-noticias/releases/29163-ppm-2019-apos-dois-anos-de-queda-rebanho-bovinocresce-0-4. (Acessado em: 04 julho 2021).

Janseem, P. H. (2010). Influence of hydrogen on rumen methane formation and fermentation balances through microbial growth kinetics and fermentation thermodynamics. Animal Feed Science and Technology, 160, 1-22. http://dx.doi.org/10.1016/j.anifeedsci.2010.07.002.

Klein, J. L., Adams, S. M., Alves Filho, D. C., Maidana, F. M., Brondani, I. L., Cocco, J. C., Volpatto, R. S., \& Robalo, S. S. (2021). Metabolic status of crossbred Charolais $\times$ Nellore cows throughout the final third of gestation and lactation. Semina: Ciências Agrárarias, 42(3), 1259-1270. https://doi.org/10.5433/1679-0359.2021v42n3p1259.

Kozloski, G. V. (2016). Bioquímica dos ruminantes. (3a ed.). Revista e Ampliada. Universidade Federal de Santa Maria. 140.

Lesschen, J. P., Van Den Berg, M., Westhoek, H. J., Witzke, H. P., \& Oenema, O. (2011). Greenhouse gas emission profiles of European livestock sectors. Animal Feed Science Technology. 166-167, 16-28. https://doi.org/10.1016/j.anifeedsci.2011.04.058.

Manço, M. X. (2020). Pastagens diferidas e bovinos suplementados: valor nutritivo, comportamento ingestivo e produção animal durante o período seco. FZEA/USP. Universidade de São Paulo. Pirassununga.

MMA, (2021). Ministério do Meio Ambiente. Biomas. Disponível em: https://antigo.mma.gov.br/biomas/amazônia.html.

Moraes, E. H. B. K., Paulino, M. F., Moraes, K. A. K., Figueiredo, D. M., Valadares Filho, S. De C., Paulino, P. V. R. E., \& Couto, V. R. M. (2009). Exigências de energia de bovinos de corte em pastejo. Revista Brasileira de Zootecnia, 38(5), 933-940. https://doi.org/10.1590/S1516-35982009000500021.

Mota, V. A. C., Fernandes, R. M., Prados, L. F., Alves Neto, J. A., Berti, G. F., Resende, F. D., \& Siqueira, G. R. (2020). Relação entre taxa de ganho na fase de crescimento e oferta de forragem na fase de terminação em bovinos Nelore. Tropical Animal Health Production, 52, 1881-1891. https://doi.org/10.1007/s11250-020-02205-w.

Palhares, J. C. P., Morelli, M., \& Novelli, T. I. (2021). Water footprint of a tropical beef cattle production system: The impact of individual-animal and feed management. Advances in Water Resources. 149. https://doi.org/10.1016/j.advwatres.2021.103853.

Pillar, V. P., Tornquist, C. G., \& Bayer, C. (2012). The Southern Brazilian grassland biome: soil carbon stocks, fluxes of greenhouse gases and some options for mitigation. Brazilian Journal of Biology, 72, 673-681. https://doi.org/10.1590/S1519-69842012000400006.

Porto, M. O., Paulino, M. F., Detmann, E., Valadares Filho, S. C., Sales, M. F. L., Cavali, J., Nascimento, M. L., \& Acedo, T. S. (2011). Ofertas de suplementos múltiplos para tourinhos Nelore na fase de recria em pastagens durante o período da seca: desempenho produtivo e características nutricionais. Revista Brasileira de Zootecnia, 40(11), 2548-2557. https://doi.org/10.1590/S1516-35982011001100037.

Ribeiro, J. L., Nussio, L. G., Mourão, G. B., Queiroz, O. C. M., Santos, M. C., \& Schmidt, P. (2009). Efeitos de absorventes de umidade e de aditivos químicos e microbianos sobre o valor nutritivo, o perfil fermentativo e as perdas em silagens de capim-marandu. Revista Brasileira de Zootecnia, 38, 230-239. https://doi.org/10.1590/S1516-35982009000200003.

Ruggieri, A. C., \& Cardoso, A. S. (2017). Balanço de carbono em sistemas de produção animal: fontes de emissão e opções de mitigação. Archivos. Latinoamericanos de Producción Animal, 25, 1-2.

Silva, E. B., Ferreira, J. R, L. G., Anjos, A. F., \& Miziara, F. (2013). Análise da distribuição espaço temporal das pastagens cultivadas no bioma Cerrado entre 1970 a 2006. Revista IDEAS, 7(1), 174-209.

Silva, F. F, S., Prado, I. N. Do, Carvalho, G. G. P. De, Silva, F. F. Da, Almeida, V. V. S., Junior, H. A. S, Paixão, M. L., \& Abreu Filho, G. (2009). Suplementação a pasto: disponibilidade e qualidade $\mathrm{x}$ níveis de suplementação x desempenho. Revista Brasileira de Zootecnia, 38, 371-389. https://doi.org/10.1590/S1516-35982010000900030.

Steinfeld, H., Gerber, P., Wassenaar, T., Castel, V., Rosales, M., \& De Haan, C. (2006). Livestock's Long Shadow: Environmental Issues and Options. Food and Agriculture Organization of the United Nations (FAO).

Van Soest, P.J. (1994). Nutritional ecology of the ruminant. 2thed. Cornell University Press, 476.

Viana, A. F. P., Cattelam, J., Cattelam, P. M. M., Klein, J. L., Adams, S. M., Machado, D. S., \& Rodrigues, L. S. (2020). Pastagens de milheto ou sorgo forrageiro para novilhos de corte em fase de crescimento. Research, Society and Development, 9(10), e069108377. http://dx.doi.org/10.33448/rsd-v9i10.8377.

USDA, (2021). Livestock and poultry: world markets and trade. Report for January 2021. Disponível em: Economics, Statistics and Market Information System. https://usda.library.cornell.edu/

Wang, T., Teague, W. R., Park, S. C., \& Bevers, S. G. H. G. (2015). Mitigation potential of different grazing strategies in the United States Southern great plains. Sustainability, 7, 13500-13521. https://doi.org/10.3390/su71013500.

White, R. R., Brady, M., Capper, J. L., Mcnamara, J. P., \& Johnson, K. A. (2015). Cow-calf reproductive, genetic, and nutritional management to improve the sustainability of whole beef production systems. Journal of Animal Science, 93, 3197-3211, https://doi.org/10.2527/jas.2014-8800. 